\title{
KAJIAN MACAM KERAPATAN TANAM TERHADAP PERTUMBUHAN DAN HASIL TIGA VARIETAS KEDELAI (Glycine max (L.) Merrill )
}

\author{
Diana Diah Utami * Sumarmi** dan Siswadi ** \\ *Fakultas Pertanian, Universitas Slamet Riyadi, Surakarta, E-mail: ditadiana17@gmail.com \\ **Fakultas Pertanian, Universitas Slamet Riyadi, Surakarta
}

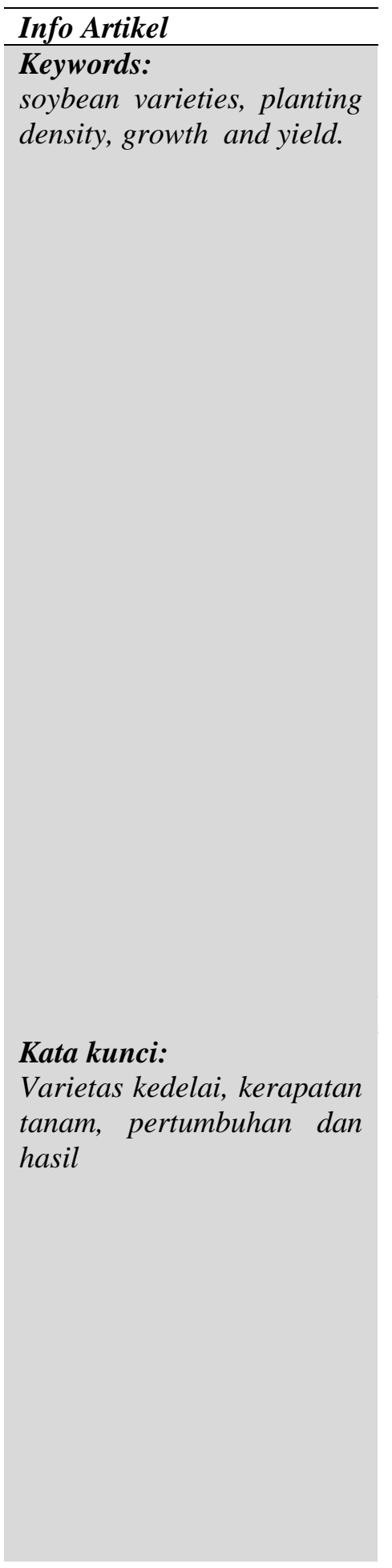

\begin{abstract}
Research on "Study of Planting Density on Growth and Yield of Three Soybean Varieties (Glycine max (L.) Merrill)" has been carried out from April 13 to July 13, 2019 in Ngalang-ngalangan Village, Senting Village, Sambi District, Boyolali District. This study aims to calculate the growth and yield of three soybean varieties by treating three kinds of planting density. In this study using a factorial Complete Randomized Block Design (RCBD) consisting of 2 factors each repeated 3 times to obtain 27 combinations. Soybean Varieties (V): V1: Grobogan, V2: Anjasmoro, V3: Malika. Kinds of Planting Density $(K): K 1: 30 \mathrm{~cm}$ $x 20 \mathrm{~cm}, K 2: 30 \mathrm{~cm} \times 30 \mathrm{~cm}, K 3: 30 \mathrm{~cm} \times 40 \mathrm{~cm}$. The results of this study indicate (1) Grobogan variety has the highest yield for number of leaves, number of pithed pods, number of empty pods, weight of wet soybean pods, weight of dried soybean seeds, weight of 100 soybean seeds. The highest average plant height was found in the Anjasmoro variety. The longest flowering age in Malika varieties is 47.22. (2) Planting density of $30 \mathrm{~cm} \times 20 \mathrm{~cm}$ (K1) has the highest yield for plant height, wet soybean pod weight, dry soybean seed weight and 100 soybean seed weight. The highest average flowering age is $30 \mathrm{~cm} \times 30 \mathrm{~cm}(\mathrm{~K} 2)$. Planting density of $30 \mathrm{~cm} \times 40 \mathrm{~cm}$ has the highest yield for number of leaves, number of empty pods, number of empty pods. (3) No interaction between planting density and three varieties occurred with respect to all parameters observed, namely plant height, number of leaves, flowering age, number of pods pithy, the number of empty pods, the weight of wet soybean pods, the weight of the soybean dry seeds, and the weight of 100 soybean seeds.
\end{abstract}

\section{Abstrak}

Penelitian tentang "Kajian Macam Kerapatan Tanam Terhadap Pertumbuhan dan Hasil Tiga Varietas Kedelai (Glycine max (L.) Merrill )" telah dilaksanakan mulai 13 April sampai 13 Juli 2019 di Desa Ngalang-ngalangan Kelurahan Senting Kecamatan Sambi Kabupaten Boyolali. Penelitian ini bertujuan untuk menghitung pertumbuhan dan hasil tiga varietas kedelai dengan perlakuan tiga macam kerapatan tanam. Dalam penelitian ini menggunakan Rancangan Acak Kelompok Lengkap (RAKL) factorial yang terdiri dari 2 faktor masing-masing diulang 3 kali sehingga diperoleh 27 kombinasi. Macam Varietas Kedelai (V) : V1 : Grobogan, V2 : Anjasmoro, V3 : Malika. Macam Kerapatan Tanam (K): K1 : $30 \mathrm{~cm}$ x $20 \mathrm{~cm}, \mathrm{~K} 2: 30 \mathrm{~cm}$ x $30 \mathrm{~cm}, \mathrm{~K} 3: 30 \mathrm{~cm}$ x $40 \mathrm{~cm}$. Hasil penelitian ini menunjukkan (1) Varietas Grobogan memiliki hasil tertinggi untuk jumlah daun, jumlah polong bernas, jumlah polong hampa, berat buah polong kedelai basah, 
berat biji kedelai kering, berat 100 biji kedelai. Tinggi tanaman rata-rata tertinggi terdapat pada varietas Anjasmoro. Umur berbunga terlama pada varietas Malika yaitu 47,22. (2) Kerapatan tanam $30 \mathrm{~cm}$ x $20 \mathrm{~cm}(\mathrm{~K} 1)$ memiliki hasil tertinggi untuk tinggi tanaman, berat buah polong kedelai basah, berat biji kedelai kering dan berat 100 biji kedelai. Umur berbunga rata-rata tertinggi pada $30 \mathrm{~cm} \times 30 \mathrm{~cm}(\mathrm{~K} 2)$. Kerapatan tanam $30 \mathrm{~cm} \times 40 \mathrm{~cm}$ memiliki hasil tertinggi untuk jumlah daun, jumlah polong hampa, jumlah polong hampa. (3) Tidak terjadi interaksi antara macam kerapatan tanam dan tiga varietas terhadap semua parameter yang diamati yaitu tinggi tanaman, jumlah daun, umur berbunga, jumlah polong bernas, jumlah polong hampa, berat buah polong kedelai basah, berat biji kedelai kering, dan berat 100 biji kedelai.

\section{PENDAHULUAN}

Kedelai (Glycine max (L) Merril) adalah salah satu tanaman polong-polongan yang menjadi bahan dasar banyak makanan dari Asia Timur contohnya kecap, tahu, dan tempe. (Iswara, Padjar, 2010). Produksi kedelai masih relatif rendah padahal permintaan kedelai beberapa tahun terakhir ini cukup tinggi seiring dengan meningkatnya pertumbuhan penduduk. (Prihatman, K, 2000.) Varietas berperan penting dalam produksi kedelai, karena untuk mencapai hasil yang tinggi sangat ditentukan oleh potensi genetiknya. Potensi hasil di lapangan dipengaruhi oleh interaksi antara faktor genetic dengan pengelolaan kondisi lingkungan. (Adisarwanto, 2006). Varietas Kedelai Grobogan mempunyai sifat polong yang tidak mudah pecah dengan potensi hasil mencapai 3,40 ton/ha. (Balitkabi, 2016). Kedelai Varietas Anjasmoro termasuk kategori berbiji besar dengan berat 100 biji kedelai mencapai 14,8 - 15,3 gram, varietas ini juga tahan terhadap penyakit karat daun dan tahan rebah serta bijinya yang mudah pecah (Raharjo, 2010). Varietas Malika memiliki polong yang lebat dan tidak mudah pecah, varietas ini juga tahan terhadap ulat grayak dan ulat jengkal (Permentan, 2007).

Jarak tanam menimbulkan pengaruh yang spesifik terhadap perilaku tanaman kedelai jarak tanam lebar lebih baik, yang dapat dilihat dari jumlah cabang produktif, jumlah buku subur yang dihasilkan sedangkan untuk jarak tanam yang rapat lebih efisien namun kurang efektif karena terjadi pemborosan benih dan sarana produksi (Santoso; Mardianti, 2011). Kerapatan yang digunakan yaitu kerapatan tanam $30 \mathrm{~cm}$ x $20 \mathrm{~cm}, 30 \mathrm{~cm}$ x $30 \mathrm{~cm}$, dan $30 \mathrm{~cm}$ x $40 \mathrm{~cm}$. Jarak tanam yang semakin rapat akan menurunkan jumlah polong bernas pertanaman karena berebutnya unsur hara (Ali, 2004). Dengan pengaturan jarak yang optimal pada proses fotosintesis dan penerimaan sinar matahari yang cukup, kedelai akan berproduksi dengan maksimal tanpa kekurangan ataupun kelebihan unsur hara. Pada jarak tanam yang renggang, energi matahari yang diserap daun untuk proses metabolisme membentuk karbohidrat dan kemampuan akar menyerap unsur hara dari dalam tanah lebih leluasa.

Berdasarkan latar belakang di atas maka penelitian tentang kajian kerapatan tanam pada tiga varietas kedelai perlu dilakukan sebagai upaya untuk mengetahui pertumbuhan dan hasil produksi tanaman kedelai.Tujuan diadakannya penelitian ini untuk mengetahui pengaruh macam kerapatan tanam terhadap pertumbuhan dan hasil tiga varietas kedelai. Diduga dengan jarak tanam $30 \mathrm{~cm} \times 30 \mathrm{~cm}$ pada varietas Anjasomoro berpengaruh terbaik terhadap pertumbuhan dan hasil tanaman kedelai

\section{BAHAN DAN METODE}

Dalam penelitian ini menggunakan Rancangan Acak Kelompok Lengkap (RAKL) faktorial dengan metode yang disusun menggunakan Split Plot yang terdiri dari 2 faktor perlakuan yaitu dengan 3 macam jarak tanam yang digunakan sebagai sub plot / anak petak dan 3 macam varietas kedelai sebagai main plot / petak utama, sehingga diperoleh 9 kombinasi perlakuan dan masingmasing diulang 3 kali.

Bahan yang digunakan adalah benih kedelai Grobogan, benih kedelai Anjasmoro, benih kedelai Hitam. Pupuk yang digunakan yaitu pupuk Urea, SP36, dan KCL sesuai dengan kebutuhan. Alat yang 
digunakan dalam pengolahan lahan adalah traktor, cangkul dan sabit. Sedangkan alat yang digunakan untuk penelitian adalah penggaris, alat tulis, meteran dan timbangan, benang.

Penelitian ini dimulai pada 14 April 2019 sampai dengan 13 Juli 2019, dilaksanakan di Dusun Ngalang-ngalangan, Desa Senting, Kecamatan Sambi, Kabupaten Boyolali, dengan ketinggian tempat 200 mdpl dan jenis tanah grumosol. Analisis selanjutnya menggunakan Uji Beda Nyata Terkecil (BNT) pada taraf 5\% untuk mengetahui perlakuan-perlakuan yang berpengaruh dan yang tidak berpengaruh.

\section{HASIL DAN PEMBAHASAN}

Hasil penelitian (Tabel 1) menunjukkan bahwa macam varietas berpengaruh nyata terhadap tinggi tanaman, jumlah daun, waktu berbunga, jumlah polong bernas, berat buah polong basah, berat kedelai kering, berat 100 biji kedelai dan jumlah polong hampa tidak berpengaruh nyata.

Tabel 1. Hasil Penelitian Pengaruh Macam Varietas Kedelai

\begin{tabular}{lrrr}
\hline \multirow{2}{*}{ PARAMETER PENGAMATAN } & \multicolumn{3}{c}{ VARIETAS } \\
\cline { 2 - 4 } & \multicolumn{1}{c}{$\mathrm{V} 1$} & \multicolumn{1}{c}{$\mathrm{V} 2$} & $\mathrm{~V} 3$ \\
\hline 1. Tinggi tanaman $(\mathrm{cm})$ & $49,93 \mathrm{~b}$ & $51,62 \mathrm{c}$ & $35,02 \mathrm{a}$ \\
2. Jumlah Daun & $25,87 \mathrm{~b}$ & $21,73 \mathrm{a}$ & $21,56 \mathrm{a}$ \\
3. Waktu berbunga & $42,56 \mathrm{a}$ & $43,78 \mathrm{a}$ & $43,22 \mathrm{~b}$ \\
4. Jumlah polong bernas & $54,78 \mathrm{~b}$ & $38,73 \mathrm{a}$ & $39,11 \mathrm{a}$ \\
5. Jumlah polong hampa & $16,00 \mathrm{a}$ & $11,91 \mathrm{a}$ & $13,53 \mathrm{a}$ \\
6. Berat buah polong basah & $784,83 \mathrm{c}$ & $623,84 \mathrm{~b}$ & $348,21 \mathrm{a}$ \\
7. Berat kedelai kering & $192,13 \mathrm{c}$ & $162,92 \mathrm{~b}$ & $93,55 \mathrm{a}$ \\
8. Berat 100 biji kedelai & $13,03 \mathrm{c}$ & $11,51 \mathrm{~b}$ & $7,00 \mathrm{a}$ \\
\hline
\end{tabular}

Keterangan : angka yang diikuti huruf sama pada baris yang sama berarti tidak berbeda nyata.

Dilihat dari Tabel tinggi tanaman diatas kedelai yang ditanam di Desa Ngalang-ngalangan, Kec. Sambi, Kab. Boyolali ini tidak dapat menghasilkan tinggi tanaman yang optimum karena waktu tanam kedelai yang tidak tepat dan kurangnya air sehingga menghambat pertumbuhan kedelai, jumlah daun varietas Grobogan (V1) memiliki rata-rata tertinggi, rata-rata umur berbunga pada semua varietas lebih lambat, karena saat itu memasuki musim kemarau panjang dan tanah yang terlalu kering sehingga kekurangan air untuk membantu dalam proses pembungaan, sehingga proses pembungaan terhambat, varietas Grobogan (V1) memiliki jumlah polong bernas terbanyak, varietas Grobogan (V1) memiliki jumlah polong hampa tertinggi, varietas Grobogan (V1) memiliki berat buah polong kedelai basah tertinggi, varietas Grobogan (V1) memiliki berat biji kedelai kering tertinggi, varietas Grobogan (V1) memiliki berat 100 biji kedelai tertinggi.

Hasil penelitian (Tabel 2) menunjukan bahwa pengaruh macam kerapatan tanamberpengaruh nyata terhadap tinggi tanaman, jumlah daun, berat buah polong basah, berat kedelai kering, dan umur berbunga, jumlah polong bernas, berat 100 biji kedelai tidak berpengaruh nyata.

Tabel 2. Hasil Penelitian Pengaruh Kerapatan Kedelai

\begin{tabular}{lrrr}
\hline Parameter Pengamatan & \multicolumn{3}{c}{ VARIETAS } \\
\cline { 2 - 4 } & \multicolumn{1}{c}{ K1 } & \multicolumn{1}{c}{ K2 3} \\
\hline 1. Tinggi tanaman $(\mathrm{cm})$ & $21,71 \mathrm{a}$ & $43,80 \mathrm{a}$ & $45,69 \mathrm{a}$ \\
2. Jumlah Daun & $42,56 \mathrm{a}$ & $22,67 \mathrm{a}$ & $24,78 \mathrm{~b}$ \\
3. Waktu berbunga & $41,80 \mathrm{a}$ & $43,78 \mathrm{a}$ & $43,22 \mathrm{a}$ \\
4. Jumlah polong bernas & $12,56 \mathrm{a}$ & $13,27 \mathrm{a}$ & $47,56 \mathrm{a}$ \\
5. Jumlah polong hampa & $705,45 \mathrm{~b}$ & $536,59 \mathrm{a}$ & $15,22 \mathrm{~b}$ \\
6. Berat buah polong basah & $184,70 \mathrm{~b}$ & $136,21 \mathrm{a}$ & $514,84 \mathrm{a}$ \\
7. Berat kedelai kering & $10,75 \mathrm{a}$ & $10,40 \mathrm{a}$ & $127,70 \mathrm{a}$ \\
8. Berat 100 biji kedelai & & $10,37 \mathrm{a}$ \\
\hline
\end{tabular}

Keterangan : angka yang diikuti huruf sama pada baris yang sama berarti tidak berbeda nyata 
Berdasarkan Tabel 2 menunjukkan bahwa penggunaan kerapatan tanam $30 \mathrm{~cm}$ x $20 \mathrm{~cm}(\mathrm{~K} 1)$ memiliki rata-rata tinggi tanaman tertinggi yaitu $47,09 \mathrm{~cm}$. Dibandingkan dengan penggunaan kerapatan tanam lainnya yaitu kerapatan tanam $30 \mathrm{~cm} \times 30 \mathrm{~cm}(\mathrm{~K} 2)$ memiliki rata- rata tinggi tanaman $43,80 \mathrm{~cm}$ sedangkan kerapatan tanam $30 \mathrm{~cm} \times 40 \mathrm{~cm}$ memiliki rata-rata tinggi tanaman $45,69 \mathrm{~cm}$. penggunaan kerapatan tanam $30 \mathrm{~cm} \times 40 \mathrm{~cm}(\mathrm{~K} 3)$ menghasilkan jumlah daun tertinggi yaitu dengan rata-rata 24,78 jika dibandingkan dengan kerapatan tanam lainnya yaitu kerapatan tanam $30 \mathrm{~cm} \times 20 \mathrm{~cm}$ (K1) dengan rata-rata 21,71 dan untuk kerapatan tanam 30cm x 30cm (K2) dengan rata-rata 22,67, kerapatan tanam $30 \mathrm{~cm} 20 \mathrm{~cm}(\mathrm{~K} 1)$ tanaman kedelai paling cepat berbunga yaitu dengan rata-rata umur berbunga 42,56 hari. Sedangkan untuk kerapatan tanam $30 \mathrm{~cm}$ x $30 \mathrm{~cm}$ (K2) memiliki rata-rata umur berbunga yaitu 43,78 dan kerapatan tanam $30 \mathrm{~cm}$ x 40 cm memiliki rata-rata umur berbunga yaitu 43,22 hari. Pada umur berbunga dengan kerapatan sempit akan mempercepat proses pembungaan, kerapatan tanam $30 \mathrm{~cm} \times 40 \mathrm{~cm}(\mathrm{~V} 3)$ memiliki jumlah polong bernas tertinggi yaitu dengan rata-rata 47,56 buah pertanaman sampel dibandingkan dengan kerapatan tanam lainnya. Penggunaan kerapatan tanam $30 \mathrm{~cm} \times 20 \mathrm{~cm}$ (V1) memiliki jumlah polong bernas dengan rata-rata 41,80 buah pertanaman sampel dan pada kerapatan tanam $30 \mathrm{~cm} \times 30 \mathrm{~cm}$ memiliki jumlah polong bernas dengan rata-rata 43,27 buah pertanaman sampel, kerapatan tanam $30 \mathrm{~cm} \times 40 \mathrm{~cm}$ (K3) memiliki jumlah polong hampa tertinggi dengan rata-rata 15,22 buah pertanaman sampel. Sedangkan pada kerapatan tanam $30 \mathrm{~cm} x$ $30 \mathrm{~cm}$ (K2) memiliki jumlah polong hampa dengan rata-rata 13,67 buah pertanaman sampel. Dan pada kerapatan tanam $30 \mathrm{~cm} \times 20 \mathrm{~cm}$ (K1) memiliki jumlah polong hampa terendah yaitu dengan rata-rata 12,56 buah pertanaman sampel, kerapatan tanam $30 \mathrm{~cm} \times 20 \mathrm{~cm}(\mathrm{~K} 1)$ memiliki berat buah polong kedelai basah tertinggi yaitu dengan rata- rata berat 705,45 gram perpetak, kerapatan tanam $30 \mathrm{~cm} \mathrm{x}$ $20 \mathrm{~cm}$ (K1) memiliki rata-rata berat biji kedelai kering tertinggi dengan rata-rata 184,70 gram perpetak, kerapatan tanam $30 \mathrm{~cm}$ x 30cm (K1) memiliki berat 100 biji kedealai tertinggi.

\section{KESIMPULAN}

1. Varietas Grobogan memiliki hasil tertinggi untuk jumlah daun dengan rata-rata 25,87 lembar pertanaman sampel, jumlah polong bernas dengan rata-rata 54,78 buah pertanaman sampel, jumlah polong hampa dengan rata-rata 16 buah pertanaman sampel, berat buah polong kedelai basah dengan rata-rata 784,83 gram per petak, berat biji kedelai kering 192,13 gram per petak, berat 100 biji kedelai dengan rata-rata 13,03 gram per 100 biji. Untuk tinggi tanaman rata-rata tertinggi pada varietas Anjasmoro dengan rata-rata $51,62 \mathrm{~cm}$. Sedangkan umur berbunga paling lama pada varietas Mallika dengan rata-rata 47,22 hari.

2. Kerapatan tanam $30 \mathrm{~cm} \times 20 \mathrm{~cm}(\mathrm{~K} 1)$ memiliki hasil tertinggi untuk tinggi tanaman dengan rata-rata $47,09 \mathrm{~cm}$, berat buah polong kedelai basah dengan rata-rata 705,45 gram per petak, berat biji kedelai kering dengan rata-rata 184,7 gram per petak, dan berat 10 biji kedelai dengan rata-rata 10,75 gram per 100 biji. Umur berbunga rata-rata tertinggi pada kerapatan tanam $30 \mathrm{~cm} \times 30 \mathrm{~cm}$ (K2) dengan rata-rata 43,78 hari. Kerapatan tanam $30 \mathrm{~cm}$ x $40 \mathrm{~cm}$ memiliki hasil tertinggi untuk jumlah daun dengan rata-rata 24,78 lembar pertanaman sampel, jumlah polong hampa dengan ratarata 47,56 buah per tanaman sampel, jumlah polong hampa 15,22 buah pertanaman sampel.

3. Tidak terjadi interaksi antara macam kerapatan tanam dan tiga varietas terhadap semua parameter yang diamati yaitu tinggi tanaman, jumlah daun, umur berbunga, jumlah polong bernas, jumlah polong hampa, berat buah polong kedelai basah, berat biji kedelai kering, dan berat 100 biji kedelai.

\section{DAFTAR PUSTAKA}

Adisarwanto. 2006. Budidaya Dengan Pemupukan Yang Efektif dan Pengopti-malan Peran Bintil Akar Kedelai. Penebar Swadaya. 107 hlm. Jakarta.

Ali, A. 2004. "Pengaruh Jarak Tanam dan Pemberian Berbagai Dosis Kotoran Ayam terhadap Pertumbuhan dan Produksi Kacang Tanah (Arachis hypogaea L.) 
Varietas Gajah”. Skripsi. Departemen Budidaya Pertanian, Fakultas Pertanian. Institut Pertanian Bogor. 108 hlm. Bogor

Balitkabi, 2016. Deskripsi Varietas Unggul Kedelai 1918-2016. Balai Penelitian Tanaman Aneka Kacang dan Umbi. Malang

Iswara dan Padjar.(2010). Kedelai Setelah Satu Dekade . Majalah Tempo. Diakses darihttp://majalah.Tempointeraktif.com/id/arsip/2010/03/29/EB/mbm. 2000329. EB133122.id.html.

Peraturan Menteri Pertanian. 2007. PERMENTAN No. 42 / Permentan / OT. 140 / 09 / 2007.

Prihatman, K. 2000. Tentang Budidaya Pertanian: Kedelai. Deputi Menegristek Bidang Pendayagunaan dan Pemasyarakatan Ilmu Pengetahuan dan Teknologi.

Raharjo, I. B. 2010. Varietas Unggul Salah Satu Upaya Tingkatkan Produksi Kedelai.

Santoso dan Mardianti. 2011. Respon Pertumbuhan Dan Hasil Tanaman Kedelai Terhadap Perbedaan Jarak Tanam Pada Fase Vegetatif. Fakultas Pertanian. Universitas Bengkulu 